\title{
Inhibition of phosphodiesterase10A attenuates morphine-induced conditioned place preference
}

\author{
Ying $\mathrm{Mu}^{1 \dagger}{ }^{\dagger}$, Zhaoxiang Ren ${ }^{1 \dagger}$, Jia Jia', Bo Gao ${ }^{1}$, Longtai Zheng ${ }^{1}$, Guanghui Wang ${ }^{1}$, Eitan Friedman ${ }^{2}$ \\ and Xuechu Zhen ${ }^{1 *}$
}

\begin{abstract}
Background: Phosphodiesterase (PDE) 10A is selectively expressed in medium spiny neurons of the striatum. Nucleus accumbens (NAc) is a key region that mediates drug reward and addiction-related behaviors. To investigate the potential role of PDE10A in the reinforcement properties of morphine, we tested the effect of MP-10, a selective inhibitor of PDE10A, on acquisition, expression, and extinction of morphine-induced conditioned place preference (CPP).

Results: The results show that $2.5 \mathrm{mg} / \mathrm{kg}$ MP-10, administered subcutaneously, significantly inhibited the acquisition of morphine-induced CPP. The same dose of MP-10 alone did not result in the CPP. Moreover, MP-10 did not alter the expression of morphine-induced CPP, but did accelerate the extinction of morphine-induced CPP. Additionally, chronic treatment with $2.5 \mathrm{mg} / \mathrm{kg}$ MP-10 decreased expression of phosphorylated CREB ( $\mathrm{pCREB}$ ), activated $\mathrm{CAMP}$ response element binding protein, in dorsomedial striatum, in shell of NAc, and in anterior cingulate cortex (ACC) as well as decreased expression of $\triangle \mathrm{FosB}$ in the shell of NAC and ACC.

Conclusion: The results suggest that inhibition of PDE10A may have therapeutic potential in the treatment of opioid addiction.
\end{abstract}

Keywords: Conditional place preference, Morphine, Nucleus accumbens, Phosphodiesterase10A, Striatum, cAMP response element binding protein, Delta FosB

\section{Background}

Drug addiction can be considered a chronic, recurrent brain disease. The conditioned place preference (CPP) paradigm has been widely used to study the conditioned rewarding effects of addictive drugs [1,2]. In this paradigm, the conditioned rewarding properties of drugs are evaluated by pairing drug effects with initially neutral cues, such as the compartment of an apparatus. After continuous medication, animals will display the conditioned place preference to the drug-related place [3]. The acquisition, expression and extinction of CPP provide a model that is important not only for investigating

\footnotetext{
* Correspondence: zhenxuechu@suda.edu.cn

${ }^{\dagger}$ Equal contributors

'Jiangsu Key laboratory for Translational Research and Therapy for Neuropsycho-disoders \& Department of Pharmacology, College of Pharmaceutical Sciences, Soochow University, 199 Ren'ai Road, Suzhou 215123, Jiangsu Province, China

Full list of author information is available at the end of the article
}

the mechanism of addiction, but also for discovering novel therapeutic approaches to addiction [1,4-6].

Cyclic nucleotides such as cyclic adenosine monophosphate (cAMP), serve as prominent second messengers in regulating a number of down-stream signaling molecules and play a critical role in a variety of cell functions. Phosphodiesterases (PDEs), which have been classified into an enzymes family consisting of 11 isozymes that hydrolyze cAMP and/or cGMP, and are essential modulators in the regulation of cAMP content in cells [7]. Among the PDE subtypes, the 10A isozyme, is a dual-substrate PDE, which is selectively expressed in medium spiny neurons (MSNs) of the striatum [8]. MSNs are striatal output neurons that represent $90 \%$ of all striatal neurons [9]. Modulation of PDE10A activity has been shown to elicit behavioral responses in experimental animals. For instance, the PDE10A inhibitor, papaverine, was found to suppress conditioned avoidance responses in rats, suggesting potential therapeutic roles in schizophrenia and in Alzhemier's disease [10]. MP-10, 2-[4-(1-methyl-4-pyridin-4-yl-1H- 
pyrazol-3-yl)-phenoxymethyl]-quinoline, an analog of papaverine with excellent potency (IC50 $=1.26 \mathrm{nM}$ ) and selectivity for PDE10A, was found to dose-dependently increase striatal cAMP and cGMP levels in CF-1 mice, and to improve negative symptoms and cognitive function in schizophrenia-like animal models [11].

On the other hand, the ventral striatum/nucleus accumbens (NAc) is the principal region which is known to mediate drug reward and addiction-related behaviors. This brain region receives dopaminergic innervation from the ventral tegmental area (VTA) in the midbrain and is known as the mesolimbic dopamine system [12,13]. Most drugs of abuse including morphine enhance dopaminergic transmission from the VTA to the NAc and to other target limbic regions such as prefrontal cortex [14-17]. It has been previously reported that the application of a PDE4 inhibitor attenuates the rewarding properties of cocaine and morphine [18]. Given the fact that PDE10A is specifically located in striatum, an important structure involved in the reward circuit, we hypothesized the PDE10A inhibitors such as MP-10 may modulate the behavioral reinforcement exerted by morphine.

Chronic exposure to drugs of abuse will give rise to persistent structural and functional changes in the central nervous system. These phenomena are usually referred as 'drug-induced neuroplasticity' and depend on changes in gene expression [19]. The cAMP response element binding protein $(\mathrm{CREB})$, as a downstream molecule in mediating the actions of CAMP and which MP-10 targets too, is an important transcriptional factor in establishing and maintaining addiction to drugs of abuse $[13,20]$. Psychostimulants increase CREB activity, as measured by increased phospho-CREB (pCREB) in multiple brain regions, including the NAc and dorsal striatum [21,22]. Phosphorylation of CREB at Ser133 activates a number of immediate early genes (IEGs) including $c$-fos. Chronic administration of drugs of abuse induces long-lasting expression of $\Delta$ FosB particularly in NAc, dorsal striatum, and prefrontal cortex; these changes persist after cessation of drug treatment $[23,24]$. The increased expression of $\Delta$ FosB was found to be associated with enhanced locomotion and with the rewarding effects of opiates $[25,26]$. In the present study we therefore also examined how modulation of PDE10A alters the expression of $\triangle F$ FosB and pCREB in NAc (core and shell), dorsomedial striatum (DMS), and anterior cingulate cortex (ACC) and their relation to morphine acquisition, expression and extinction in the CPP model.

\section{Results}

MP-10 suppressed the acquisition but not the expression of morphine CPP

We first tested if MP-10 suppressed the acquisition of morphine CPP. As shown in Figure 1A, after chronic administration of morphine, animals spent significantly more time in the drug-paired compartment $\left(\mathrm{F}_{(5,53)}=7.90, \mathrm{P}<\right.$ 0.0001). Significant inhibition of morphine-induced CPP was observed at $2.5 \mathrm{mg} / \mathrm{kg} \mathrm{MP}-10 \quad(\mathrm{t}=5.457$, $\mathrm{P}<0.001$ compared with morphine group).

We also tested if administration of MP-10 alters the expression of established morphine CPP. As shown in Figure $1 \mathrm{~B}$, acute injection of MP-10 $(2.5 \mathrm{mg} / \mathrm{kg}) 30 \mathrm{~min}$ prior to placement into the apparatus produced no significant attenuation of the previously established expression of morphine CPP.

\section{Chronic low dose MP-10 treatment did not produce CPP}

In order to elucidate why high doses of MP-10 failed to suppress morphine CPP, we investigated if MP-10 alone could lead to CPP. As $2.5 \mathrm{mg} / \mathrm{kg}$ of MP-10 did not produce CPP in our preliminary experiment, we thus omitted $1.25 \mathrm{mg} / \mathrm{kg}$ group. As shown in Figure 2, after 8 days of conditioning sessions, administration of morphine caused a significant preference for the drug-paired compartment $\left(\mathrm{F}_{(4,42)}=4.941, \mathrm{P}<0.01\right)$, whereas $\mathrm{MP}-10(2.5 \mathrm{mg} / \mathrm{kg}$ and $5.0 \mathrm{mg} / \mathrm{kg}$, s.c.) elicited no significant CPP or aversion. At the dose of $10 \mathrm{mg} / \mathrm{kg} \mathrm{MP}-10$ induced a marginal CPP preference score. This may contribute to the finding that at this high dose of MP-10 the drug did not suppress morphine CPP. The apparent CPP preference score obtained with the high dose MP-10 completely disappeared when the test was re-run one week following the first test. Thus, it appears that at the high dose of MP-10 the drug produces a weak and temporary preference. However, this dose also produced catalepsy (descent latency: $47 \pm 8.5 \mathrm{sec}$ for $2.5 \mathrm{mg} / \mathrm{kg}$ and $116 \pm 15.8 \mathrm{sec}$ for $10.0 \mathrm{mg} / \mathrm{kg}$ ). We thus used $2.5 \mathrm{mg} / \mathrm{kg}$ of MP-10 for the extinction experiments.

\section{MP-10 treatment facilitates the extinction of morphine CPP} Repeated measure two-way ANOVA of the data (Figure 3) reveals a significant difference in time $\left(\mathrm{F}_{(4,}, 80\right)=3.030$, $\mathrm{P}<0.05)$ and drug $\left(\mathrm{F}_{(2,80)}=13.64, \mathrm{P}<0.001\right)$, but not in time $\times$ drug interaction $\left(\mathrm{F}_{(8,80)}=0.9646, \mathrm{P}>0.05\right)$. Bonferroni post-test analysis revealed significant differences in the time spent in the morphine-paired compartment at the post-conditioning test $(t=2.734, \mathrm{P}<0.05)$, the first extinction test $(\mathrm{t}=3.451, \mathrm{P}<0.01)$, and the second extinction test $(\mathrm{t}=3.226, \mathrm{P}<0.01$ ) between $\mathrm{Mor} / \mathrm{Veh}$ and $\mathrm{Sal} / \mathrm{Veh}$ groups. Rats treated with $2.5 \mathrm{mg} / \mathrm{kg} \mathrm{MP}-10$ during extinction training exhibited significant differences only at the post-conditioning test $(\mathrm{t}=2.793, \mathrm{P}<0.05)$ and the first extinction test $(t=2.782, \mathrm{P}<0.05)$. No preference was detected at the second and third extinction tests. At the second extinction test, a significant difference between Mor/ Veh and Mor/MP-10 $(\mathrm{t}=2.778, \mathrm{P}<0.05)$ groups in the time spent in the drug-paired compartment was obtained. The results suggest that $2.5 \mathrm{mg} / \mathrm{kg} \mathrm{MP}-10$ treatment facilitates extinction of morphine-acquired CPP. 

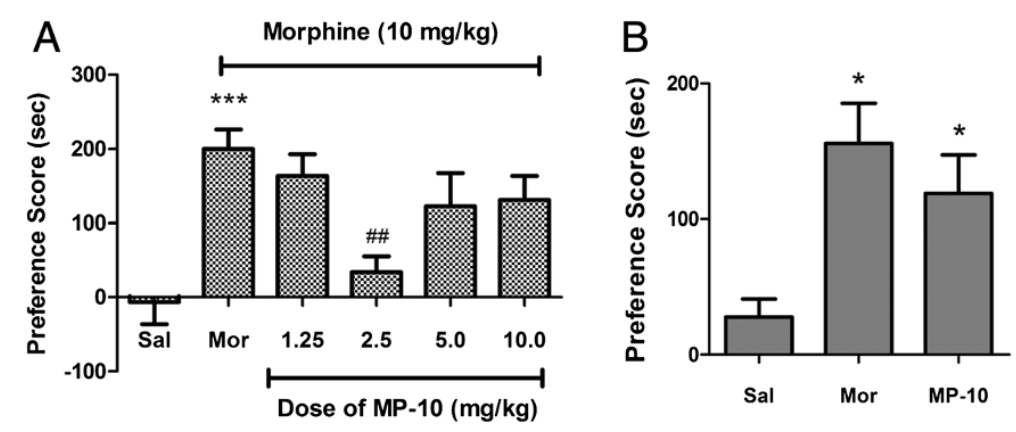

Figure 1 MP-10 suppressed the acquisition (A) but not the expression (B) of morphine CPP. (A) MP-10 (1.25-10 mg/kg, S.C.) or vehicle $\left(2 \mathrm{ml} / \mathrm{kg}\right.$, s.c.) were administered $30 \mathrm{~min}$ before morphine $\left(10 \mathrm{mg} / \mathrm{kg}\right.$, s.c.) or saline $\left(2 \mathrm{ml} / \mathrm{kg}\right.$, s.c.) during the conditioning sessions. ${ }^{* *} \mathrm{P}<0.001$ indicates difference in comparison with saline group, whereas \#\#P $<0.01$ indicates comparison with the morphine group. $\mathrm{N}=6-13$ per group. (B) Pretreatment of MP-10 (2.5 mg/kg) 30 min prior to placement in the apparatus on post-conditioning test day. ${ }^{*} \mathrm{P}<0.05$, compare with saline group, $\mathrm{N}=6-10$ per group. CPP scores were assessed as the difference of time spent in the drug-paired compartment between the post and pre-conditioning phases. Data were expressed as mean \pm SEM.

\section{MP-10 causes long-lasting changes in expression of pCREB and $\triangle$ FosB immunoreactivity in morphine CPP tested rats}

CREB and $\triangle F$ FosB are important transcriptional factors which are believed to play important roles in the development of CPP. Acute morphine and PDE inhibition, by altering the $\mathrm{cAMP} / \mathrm{cGMP}$ content, were shown to increase the expression of pCREB [22,27] and $\triangle$ FosB [28]. We therefore, investigated the potential long-lasting effects of MP-10 on the expression of these transcription factors $48 \mathrm{~h}$ hours after acquisition of morphine CPP. As shown in Figures 4 and 5, two-way ANOVA analyses indicate that morphine significantly increased in the number of pCREB- immunoreactive cells in DMS, ACC, and

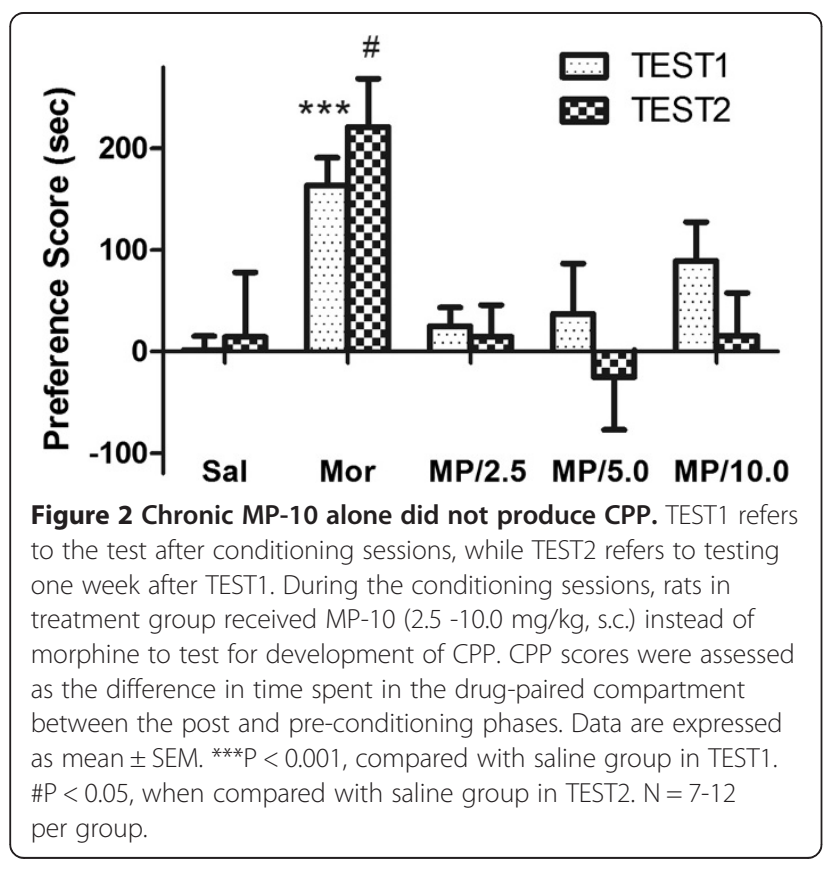

NAc shell, but not in NAc core in rats that developed morphine CPP. Although MP-10 alone at the dose of $2.5 \mathrm{mg} / \mathrm{kg}$ did not produce a long-lasting increase in the number of pCREB-positive nuclei in any of the regions assessed, but significantly decreased morphine-induced pCREB expression in DMS $\left(\mathrm{F}_{(1,16)}=4.643, \mathrm{P}<0.05 ; \mathrm{t}=\right.$ $2.965, \mathrm{P}<0.05)$ and $\mathrm{ACC}\left(\mathrm{F}_{(1,16)}=4.548, \mathrm{P}<0.05 ; \mathrm{t}=\right.$ $2.634, \mathrm{P}<0.05)$. In contrast, $10.0 \mathrm{mg} / \mathrm{kg} \mathrm{MP}-10$ alone produced significant long-lasting increases in the number of pCREB- immunoreactive cells in NAc shell $\left(\mathrm{F}_{(1,16)}=9.666, \mathrm{P}<0.01 ; \mathrm{t}=3.091, \mathrm{P}<0.05\right)$; but not in DMS, NAc shell, and ACC.

$\triangle F o s B$ is a splice variant of the FosB protein and belongs to the Fos family. Chronic administration of drugs of abuse, including morphine, induces long-lasting expression of $\Delta$ fosB that persists even after cessation of drug treatment [23]. In agreement with previous observation, we detected (Figures 6 and 7) that morphine produced significant increases in the number of $\triangle$ FosBimmunoreactive cells in DMS, NAc shell, and ACC. MP-10 alone, either at $2.5 \mathrm{mg} / \mathrm{kg}$ or $10.0 \mathrm{mg} / \mathrm{kg}$, increased the number of $\triangle$ FosB- positive nuclei in NAc shell $\left(\mathrm{F}_{(1,16)}=11.24, \mathrm{P}<0.01 ; \mathrm{t}=2.787, \mathrm{P}<0.05\right.$ and $\left.\mathrm{F}_{(1,16)}=10.23, \mathrm{P}<0.01 ; \mathrm{t}=4.143, \mathrm{P}<0.01\right)$ and $\mathrm{ACC}$ $\left(\mathrm{F}_{(1,16)}=26.20, \mathrm{P}<0.001 ; \mathrm{t}=2.869, \mathrm{P}<0.05\right.$ and $\mathrm{F}_{(1,16)}=$ 8.606, $\mathrm{P}<0.01 ; \mathrm{t}=2.749, \mathrm{P}<0.05)$. However, inhibition of PDE10A by MP-10 $(2.5 \mathrm{mg} / \mathrm{kg})$ significantly decreased morphine-induced expression of $\triangle \mathrm{FosB}$ in ACC $(\mathrm{t}=4.370$, $\mathrm{P}<0.001)$ and NAc shell $(\mathrm{t}=2.477, \mathrm{P}<0.05)$. In contrast, $10 \mathrm{mg} / \mathrm{kg} \mathrm{MP}-10$ enhanced morphine-induced expression of $\triangle$ FosB in NAc shell $(\mathrm{t}=3.710, \mathrm{P}<0.01)$, ACC $(\mathrm{t}=3.455$, $\mathrm{P}<0.01)$, and DMS $(\mathrm{t}=4.097, \mathrm{P}<0.01)$.

\section{Discussion}

The cAMP signaling cascade plays a critical role in the development and maintenance of addiction to drugs of 


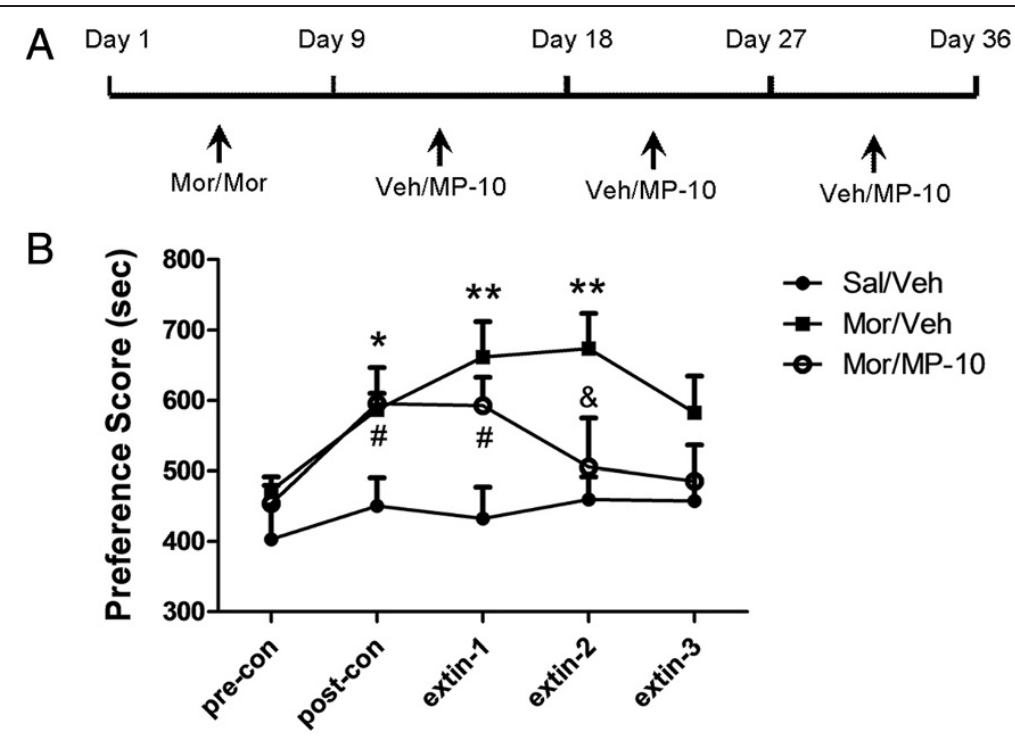

Figure 3 MP-10 treatment ( $2.5 \mathrm{mg} / \mathbf{k g}$, s.c.) facilitates the extinction of morphine CPP. Figure (A) shows the treatment time line and figure (B) shows the results. No compartment preferences developed in rats receiving saline throughout the experimental procedure (Sal/Veh). Rats administered vehicle in extinction sessions show spontaneous extinction tendency until the third extinction test (Mor/Neh). Rats receiving MP-10 (2.5 mg/kg) exhibited complete extinction of preference by the second and third extinction test (Mor/MP-10). The place preference score is defined as the difference in time spent in drug-paired compartments. Data are expressed as mean $\pm \mathrm{SEM}$. ${ }^{*} \mathrm{P}<0.05$, ${ }^{* * P}<0.01$ compared between Mor/Neh and Sal/Veh group. \#P $<0.05$ compared between Mor/MP-10 and Sal/Veh group. \& P $<0.05$ compared between Mor/Neh and Mor/MP-10. $\mathrm{N}=6-7$ per group.

abuse [29]. Modulation of cAMP content by altering its production or hydrolysis has become an important focus in developing potential therapeutic approaches for addiction. For instance, a D1 receptor antagonist, which blocks D1 receptor-mediated stimulation of cAMP, or a D2 receptor antagonist, which abolishes D2 receptormediated inhibition of cAMP formation, was shown to have some potential therapeutic effects in drug abuse $[30,31]$. PDE is a large family of enzymes that play a key role in modulation of cAMP and/or cGMP cellular content via their ability to hydrolyze the two second messengers. It was shown that administration of the PDE4 inhibitor rolipram $[18,32]$ and the PDE9 inhibitor BAY73-6691 [33] suppressed both the acquisition of cocaine CPP and its extinction. Unlike the wide distribution of PDE4 in brain, PDE10A is selectively expressed in medium spiny neurons (MSNs) of striatum. The present study provides evidence that selective inhibition of PDE10A significantly attenuates the acquisition of, and facilitates the extinction of morphine-induced CPP. This suggests that PDE10A-mediated breakdown of cyclic nucleotide in striatal neurons may participate in the reward pathway of addictive drugs. Our results thus provided the first evidence for the potential therapeutic effect of a PDE10A inhibitor in morphine addiction. It should be noted that acute inhibition of PDE10 failed to alter the expression of morphine-induced CPP, suggesting that the neuroplasticity induced by repeated MP-10 treatment may underlie drug-attenuated acquisition, and drug-facilitated extinction.

MP-10 specifically inhibited PDE10A of MSN in striatum and increased cAMP concentration in these neurons, an effect that functionally resembles D1 receptor stimulation or D2 receptor inhibition with regard to the production of cAMP. It is well known that almost all drugs of abuse exert their rewarding effect through the release of dopamine and activation of dopamine receptors in nucleus accumbens (NAc) [16]. Systemic administration of D2 receptor antagonists have been shown to reverse morphine-induced CPP [31,34]. Those observations are in line with the effect of $2.5 \mathrm{mg} / \mathrm{kg} \mathrm{MP}-10$ on morphine-induced CPP in the current study. It is reasonable to assume that this effects may be attributed to the increase in cAMP content in striatum by MP-10, as it has been shown before that $3 \mathrm{mg} / \mathrm{kg}$ of MP-10 significantly elevated striatal cAMP and cGMP [27]. It should be noted that higher doses of MP-10 $(5,10 \mathrm{mg} / \mathrm{kg})$ failed to inhibit morphine CPP. One possible explanation for this maybe that an optimal intracellular concentration of cAMP/cGMP is required and that higher levels result in damaged neuronal functions. In support, we found that MP-10 (10 mg/kg) enhanced morphine-induced expression of $\triangle$ FosB in NAc shell, ACC, and DMS. Indeed, we found that both 5 and $10 \mathrm{mg} / \mathrm{kg}$ of $\mathrm{MP}-10$ produced catalepsy as tested with a vertical wire-mesh grid, in which the descent latency of $5,10 \mathrm{mg} / \mathrm{kg}$ of MP-10 is 


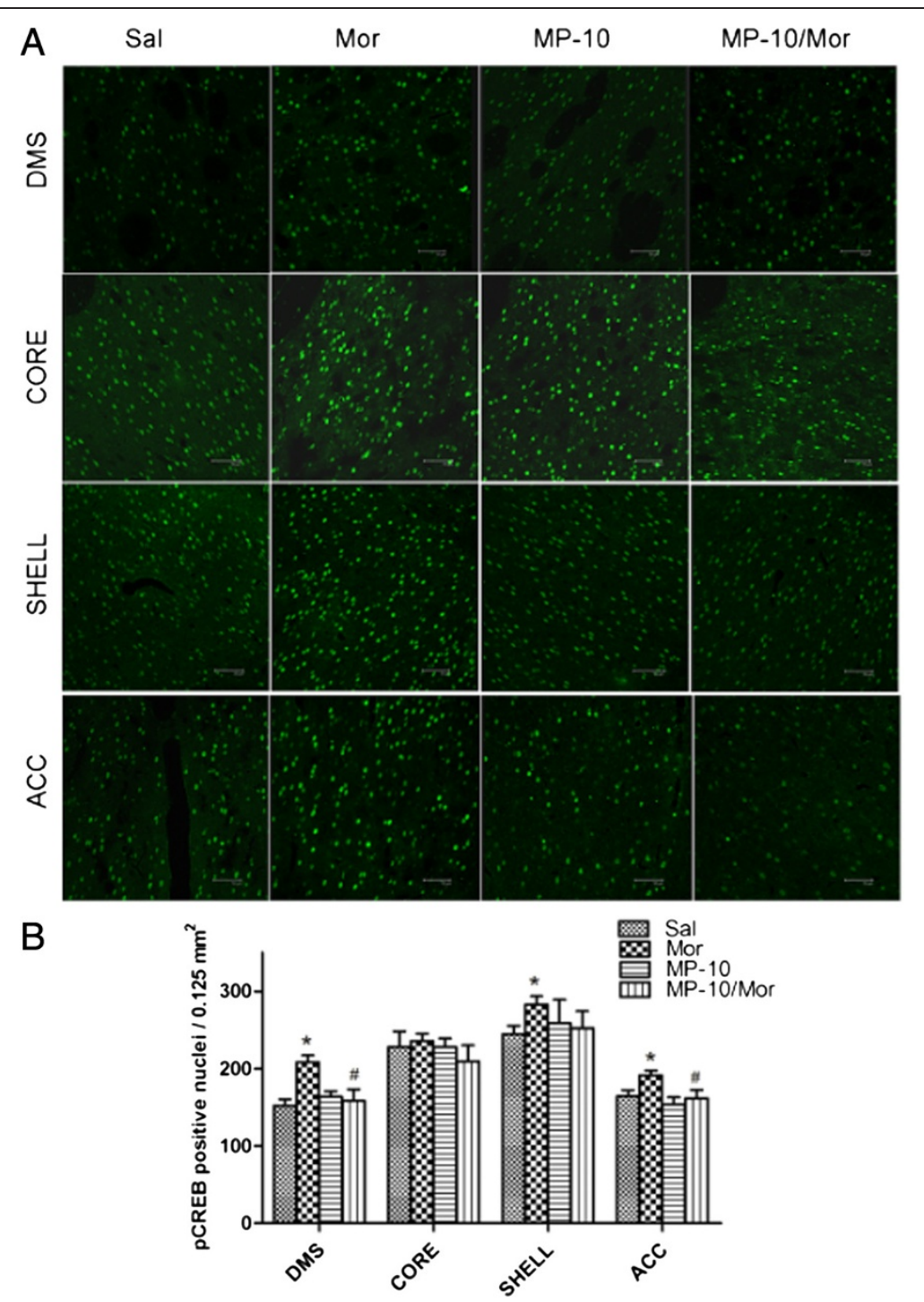

Figure 4 MP-10 (2.5 mg/kg) causes long-lasting changes in expression of pCREB immunoreactivity. (A) Immunofluorescence images of pCREB in different brain areas from rats receiving saline (Sal, $2 \mathrm{ml} / \mathrm{kg}$, s.c.), morphine (Mor, $10 \mathrm{mg} / \mathrm{kg}$, s.c.), MP-10 (MP-10, 2.5 mg/ $/ \mathrm{kg}$, s.c.) or a combination of both drugs (MP-10/Mor). MP-10 was administered 30 min prior to morphine and after CPP testing (scale bar represents $50 \mu \mathrm{m}$ ). (B) Quantification of pCREB positive nuclei. Data are expressed as mean \pm SEM and analyzed by two-way ANOVA followed by Bonferroni posttests. ${ }^{*} \mathrm{P}<0.05$ when comparing between morphine and saline groups. $\# \mathrm{P}<0.05$ when comparing the morphine group to the drug combination group. $\mathrm{N}=5$ per group. DMS: dorsomedial striatum; CORE: NAC core; SHELL: NAC shell; ACC: anterior cingulate cortex.

significantly more than that of $2.5 \mathrm{mg} / \mathrm{kg}$ (data not shown). Another possible cause maybe attributed to the transit and weak CPP (Figure 2) observed when a high dose of MP-10 is administered alone.

To further understand the neurobiological mechanisms underlying the effect of PDE10A inhibition on morphineinduced CPP, we checked the expression of $\mathrm{pCREB}$ and $\triangle F$ osB in nucleus accumbens (NAc), dorsomedial striatum (DMS), and anterior cingulate cortex (ACC). In agreement with previous reports [25,35], we detected elevations of pCREB and $\triangle$ FosB in rat brain regions of morphine CPP animals 48 hours after the last drug administration. MP-10 at the dose of $2.5 \mathrm{mg} / \mathrm{kg}$ significantly decreased morphineinduced pCREB expressions in DMS and ACC as well as the expression of $\triangle$ FosB in NAc shell and ACC. This may be a result of negative feedback of striatal neurons onto midbrain cells. There are a minority of MSNs which make up the so-called "patch" population and target only dopaminergic cells in the midbrain, ventral tegmental area (VTA) and substantia nigra pars compacta (SNc) $[9,36]$. MP-10 targeted and activated striatal MSNs including those projecting to the midbrain and the increased release of GABA from those MSNs may have altered the disinhibition caused by activation of mu-opioid 


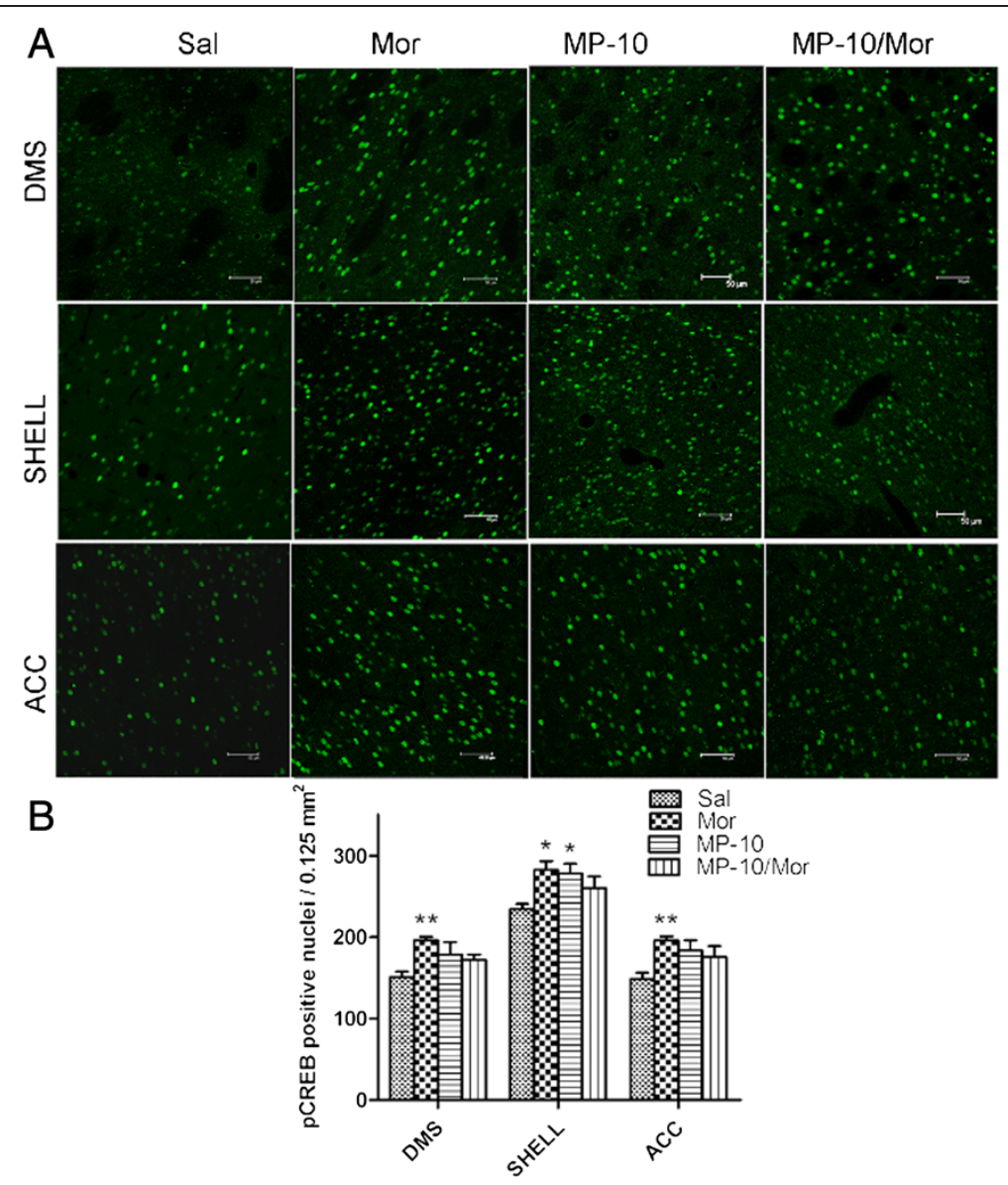

Figure 5 MP-10 (10.0 mg/kg) causes long-lasting changes in expression of pCREB immunoreactivity. (A) Immunofluorescence images of pCREB in different brain areas from rats receiving saline (Sal, $2 \mathrm{ml} / \mathrm{kg}$, s.c.), morphine (Mor, $10 \mathrm{mg} / \mathrm{kg}$, s.c.), MP-10 (MP-10, $10.0 \mathrm{mg} / \mathrm{kg}$, s.c.) or a combination of both (MP-10/Mor, MP-10 was administared 30 min prior to morphine) after CPP testing (scale bar represents $50 \mu \mathrm{m})$. (B) Quantification of pCREB positive nuclei. Data are expressed as mean \pm SEM and analyzed by two-way ANOVA followed by Bonferroni posttests. ${ }^{*} \mathrm{P}<0.05$, ${ }^{* *} \mathrm{P}<0.01$ when compared with saline group. $\mathrm{N}=5$ per group. DMS: dorsomedial striatum; SHELL: NAC shell; ACC: anterior cingulate cortex.

receptors in VTA [9], thus, abolishing morphine-induced dopamine release in striatum and PFC [16]. This is supported by the observation that MP-10 blocks Damphetamine-induced dopamine efflux in NAc through D1-regulated feedback control of midbrain dopamine neurons [37]. As a result, morphine-induced increases of pCREB in ACC and of $\triangle F$ osB in NAc shell and ACC were thus suppressed by MP-10. Ultimately and importantly, morphine-induced CPP was also inhibited. In contrast to the effect of $2.5 \mathrm{mg} / \mathrm{kg} \mathrm{MP}-10$, administration of $10 \mathrm{mg} / \mathrm{kg}$ of the drug enhanced morphine-induced $\mathrm{PCREB}$ and $\triangle$ FosB in DMS, NAc shell, and ACC. This may provide a potential explanation for why $10.0 \mathrm{mg} / \mathrm{kg} \mathrm{MP}-10 \mathrm{did}$ not inhibit the acquisition of morphine CPP. Since it is known that $\triangle$ FosB plays an essential role in mediating a state of prolonged sensitization to addictive drugs this may underlie the increased drive and motivation for drug seeking behavior [25]. Therefore, MP-10 (2.5 mg/kg) attenuated morphine-increased $\triangle$ FosB levels in ACC and shell of NAc may provide a potential molecular mechanism for the antirelapse effect of the drug. Given the fact that both morphine and MP-10 alone increased the expression of $\Delta$ FosB, it will be of great interest to investigate how MP-10 inhibits the expression of $\Delta$ FosB in those brain regions.

We did not detect any significant changes in expression of either pCREB or $\triangle$ FosB in NAc core among the experimental groups. Interestingly, a previous study showed that nicotine dependent conditioning resulted in elevated pCREB level in the NAc shell but not in NAc core in mice [38]; and cocaine CPP was accompanied by significant increases in expression of Fos in the shell rather than the core of NAc [39]. In addition, it was reported that decreased pCREB expression was observed in palladium of rats withdrawing from morphine-induced behavioral sensitization [40]. The reason for this discrepancy may be associated with the 


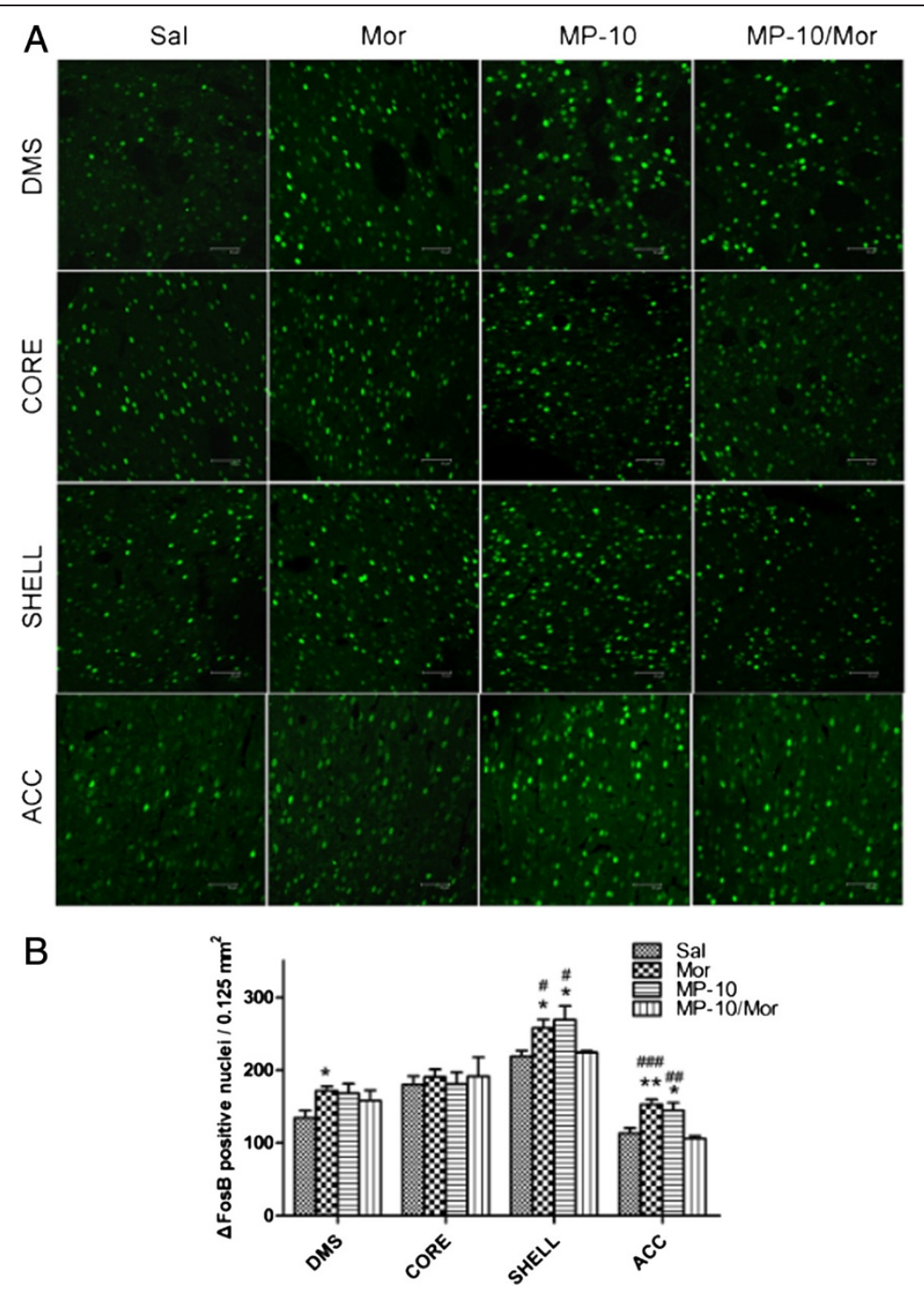

Figure 6 MP-10 (2.5 mg/kg) causes long-lasting changes in expression of $\Delta$ FosB immunoreactivity. (A) Immunofluorescence images of $\Delta$ FosB in different brain areas from rats that received saline (Sal, $2 \mathrm{ml} / \mathrm{kg}$, s.c.), morphine (Mor, $10 \mathrm{mg} / \mathrm{kg}$, s.c.), MP-10 (MP-10, $2.5 \mathrm{mg} / \mathrm{kg}$, s.c.) or combination of both MP-10/Mor, (MP-10 was administration 30 min prior to morphine and after CPP testing (scale bar, $50 \mu m$ ). (B) Quantification of $\triangle$ FosB-positive nuclei. Data are expressed as mean \pm SEM and analyzed by two-way ANOVA followed by Bonferroni posttests. ${ }^{*} P<0.05$, ${ }^{* *} \mathrm{P}<0.01$ when compared with saline group. \#P $<0.05$, \#\#P $<0.01$, \#\#\# $<0.001$ when compared with MP-10/Mor group. $N=5$ per group. DMS: dorsomedial striatum; CORE: NAC core; SHELL: NAC shell; ACC: anterior cingulate cortex

different paradigms employed and/or the distinct functional involvement of different brain regions in response to drug of abuse.

\section{Conclusion}

In conclusion, we found that MP-10 administration at the dose of $2.5 \mathrm{mg} / \mathrm{kg}$ suppressed the acquisition of morphineinduced CPP through inhibiting morphine- induced increases in $\mathrm{PCREB}$ and $\triangle \mathrm{FosB}$ in brain regions within the rewarding circuit, such as dorsomedial striatum, shell of nucleus accumbens, and anterior cingutate cortex. Our results reveal that MP-10 can inhibit morphine -induced CPP and thus it may have therapeutic potential in opioid abuse.

\section{Methods}

Animals and drugs

\section{Animals}

Male Sprague-Dawley rats, weighed 150-200 g, were purchased from Shanghai Laboratory Animal Co. LTD (Shanghai, China). The rats were habituated for one week prior to the experiments. All animals were housed in constant temperature $\left(21 \pm 2^{\circ} \mathrm{C}\right)$ and humidity (about 60\%) with a $12 \mathrm{~h}$ light/dark cycle. Food and water were available ad libitum. All experimental protocols were approved by the Institutional Animal Care and Use Committee of Soochow University and were conducted in accordance with the U.S. National Institutes of Health Guide for the Care and Use of Laboratory Animals. 


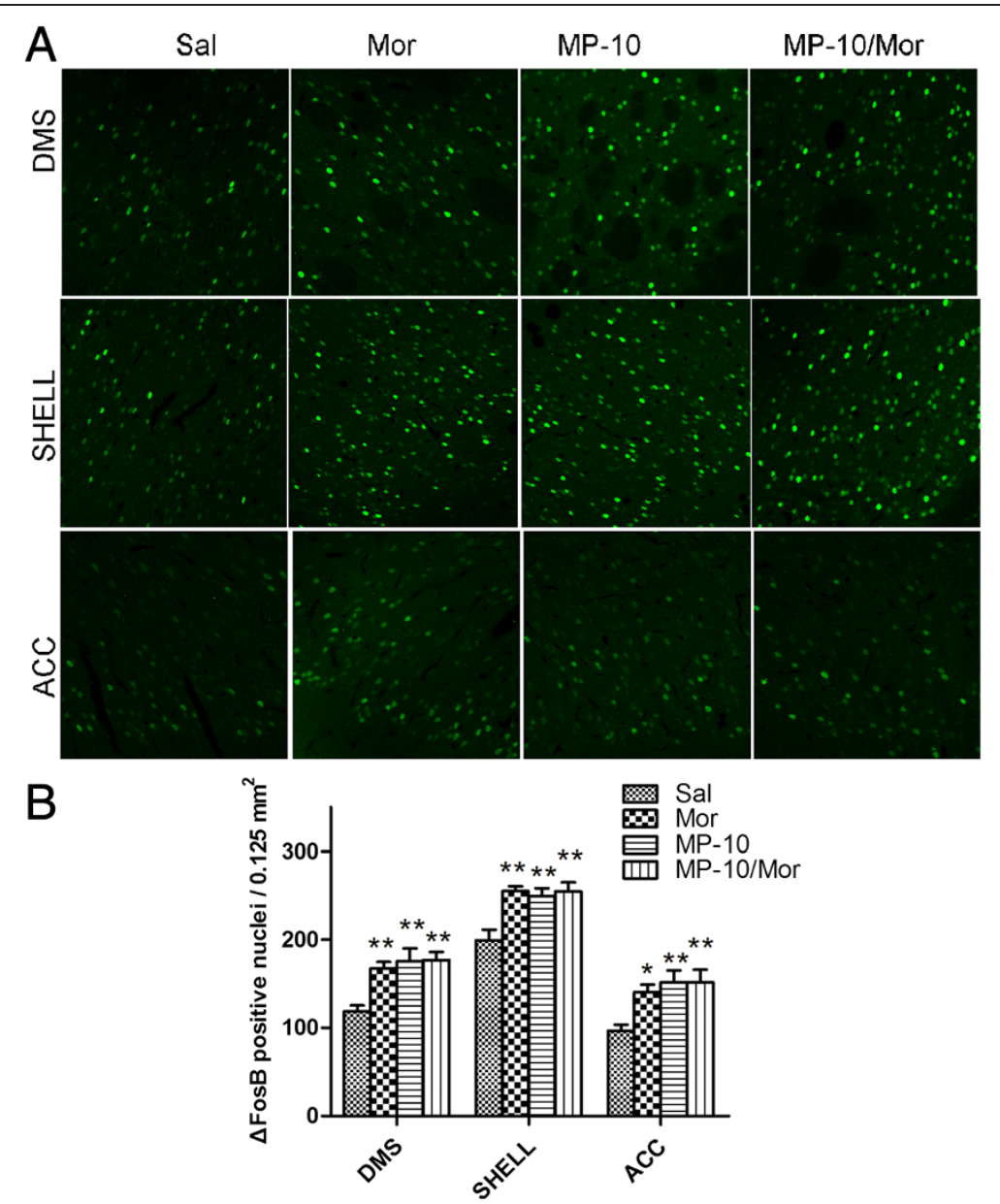

Figure 7 MP-10 (10.0 mg/kg) causes long-lasting changes in expression of $\Delta$ FosB immunoreactivity. (A) Immunofluorescence images of $\Delta$ FosB in different brain areas from rats that received saline (Sal, $2 \mathrm{ml} / \mathrm{kg}$, s.c.), morphine (Mor, $10 \mathrm{mg} / \mathrm{kg}$, s.c.), MP-10 (MP-10, $10.0 \mathrm{mg} / \mathrm{kg}$, s.c.) or combination of both MP-10/Mor, (MP-10 was administration 30 min prior to morphine) after CPP testing (scale bar, 50 um). (B) Quantification of $\triangle$ FosB-positive nuclei. Data are expressed as mean \pm SEM and analyzed by two-way ANOVA followed by Bonferroni posttests. ${ }^{*} P<0.05$, ${ }^{* *} \mathrm{P}<0.01$, when compared with saline group. $\mathrm{N}=5$ per group. DMS: dorsomedial striatum; SHELL: NAC shell; ACC: anterior cingulate cortex.

\section{Drugs}

MP-10 (2-[4-(1-methyl-4-pyridin-4-yl-1H-pyrazol-3-yl)-phenoxymethyl]-quinoline succinic acid), purchased from Shanghai Pharmaresource Inc, was dissolved in 5\% 2hydroxypropyl- $\beta$-cyclodextrine $/ 0.5 \%$ carboxymethylcellulose sodium for subcutaneous injection (s.c.). Morphine hydrochloride was purchased from Shenyang First Pharmaceutical Factory, Northeast Pharmaceutical Group Corp. (Shenyang, China) and dissolved in saline. Controls were injected (s.c.) with the same volume of either 5\% 2-hydroxypropyl- $\beta$ -cyclodextrine $/ 0.5 \%$ carboxymethylcellulose sodium or saline. All drugs or vehicles were administered with a volume of $2 \mathrm{ml} / \mathrm{kg}$.

\section{Behavioral procedures}

\section{Apparatus}

The apparatus for CPP conditioning and testing consisted of eight identical plexiglas/polyvinyl chloride (PVC) boxes purchased from Jiliang Ltd. (Shanghai, China). The boxes were composed of two compartments with distinct visual and textural cues. One compartment had white walls and a fine wire mesh floor $\left(0.5 \times 0.5 \mathrm{~cm}^{2}\right)$, whereas another had black walls and a wide grid floor with metal rods spaced $1.6 \mathrm{~cm}$ apart. These two compartments were separated by a removable wall with an arched gateway to allow the free movement of animals through the whole apparatus during the testing session, whereas during the conditioning session, the separating wall was closed to restrict the animal in their designated conditioning compartment. The movements within the compartments and time spent in each compartment were recorded and automatically measured by a computer through interruption of infrared beams by the test animals.

\section{Conditioned place preference (CPP)}

Animals were habituated in the test room for $1 \mathrm{hr}$ before the experiment began. The procedures were previously 
described and used with minor modification [1,4-6]. The 10-day CPP procedure included three main phases: a pre-conditioning test session, eight daily conditioning sessions and a post-conditioning test session. On day 0 , the base-line preferences of animals were determined by placing them for 15 minutes in the apparatus with the separating wall and the arched gateway present (preconditioning test). Rats that spent more than $70 \%$ of the session time in one compartment were excluded because of their strong unconditioned preference. During the second phase, conditioning was performed using an unbiased, balanced protocol, after the separating wall was inserted to restrict movement of the animal. The order of injection (drug or vehicle), and the compartment paired with the drug or saline, was counterbalanced within each group. In this phase, each rat was trained for eight consecutive days with alternative injections of morphine (10 $\mathrm{mg} / \mathrm{kg}$, s.c.) and saline $(2 \mathrm{ml} / \mathrm{kg}$, s.c.). On days $1,3,5$, and 7 , rats were injected with morphine and immediately confined to the drug-paired compartment for $45 \mathrm{~min}$ before returning to their home cages. On day $2,4,6$, and 8 , rats were injected with saline and confined for $45 \mathrm{~min}$ in the opposite compartment (saline-paired compartment). On the third phase, day 9 , the separating wall was reversed again with the arched gateway opening to allow rats to freely explore for $15 \mathrm{~min}$. The time spent in each compartment during this session was recorded (post-conditioning test). The CPP score was defined as the difference of the time spent in the drug-paired compartment during the pre- and post-conditioning tests.

\section{Experimental protocols}

To study the effect of MP-10 on the acquisition of morphine-induced CPP, the same general procedure as described above was used to develop morphine CPP, except for the following modifications: MP-10 (1.25-10 mg $/ \mathrm{kg}$, s.c.) or vehicle was administered $30 \mathrm{~min}$ before each morphine or saline conditioning sessions. On day 9, the animals were tested for morphine CPP in a drug free state. An additional experiment was carried out to evaluate whether MP-10 alone could induce CPP: rats received MP-10 (2.5-10 mg/ $\mathrm{kg}$, s.c.) instead of morphine following the above-mentioned conditioning procedure. In this experiment, administration of $10.0 \mathrm{mg} / \mathrm{kg}$ MP-10 caused a mild preference trend, so a second test was repeated one week afterward.

To observe the effect of MP-10 on the expression of established morphine CPP, morphine $(10 \mathrm{mg} / \mathrm{kg}$, s.c.) was used during the conditioning sessions in all the groups except the saline-treated group. On the test day, vehicle $(2 \mathrm{ml} / \mathrm{kg}$, s.c.) or MP-10 (2.5 $\mathrm{mg} / \mathrm{kg}$, s.c.) was injected $30 \mathrm{~min}$ prior to placement in the apparatus, with free access to the two compartments for $15 \mathrm{~min}$.

The effect of MP-10 $(2.5 \mathrm{mg} / \mathrm{kg})$ on extinction to morphine CPP was determined in a separate set of animals.
The general procedure described above was used to establish morphine CPP. After testing for the expression of CPP in a drug-free state on the day 9, extinction conditioning sessions were initiated. This extinction procedure is very similar to the original acquisition training. On day $10,12,14,16, \mathrm{MP}-10$ (2.5 mg/kg, test group) or vehicle ( $2 \mathrm{ml} / \mathrm{kg}$, control group) was administered prior to restricting the animals to the same drug-paired compartment as in acquisition training, whereas on day 11, $13,15,17$, vehicle was administered prior to exposure to the saline-paired compartment before placement in the home cage. This extinction procedure was repeated three times (Days 10-17, 19-26, and 28-35). During this extinction procedure, rats in the saline group received daily vehicle $(2 \mathrm{ml} / \mathrm{kg})$ injections prior to alternating drug-paired or saline-paired compartment placement. On day 18,27 , and 36 , the place preference was tested by allowing rats free access for $15 \mathrm{~min}$. The place preference score is defined as the time spent in drug-paired compartments. Extinction of place preference occurred when there was no significant difference in time spent in drug-paired and saline-paired chambers among groups that were previously exhibited morphine CPP.

\section{Immunofluorescence Procedure \\ Tissue preparations}

In the experiment of the effect of MP-10 $(2.5 \mathrm{mg} / \mathrm{kg}$ and $10.0 \mathrm{mg} / \mathrm{kg}$ ) on the acquisition of morphine-induced CPP, immediately after the post-conditioning test had finished, rats ( $\mathrm{n}=5$ animals per group) were deeply anesthetized with sodium pentobarbital $(100 \mathrm{mg} / \mathrm{kg}$, i.p.) and perfused transcardially with saline, followed by $4 \%$ paraformaldehyde in $0.1 \mathrm{M}$ phosphate-buffered saline (PBS, pH 7.4). The brains were then removed and postfixed overnight at $4^{\circ} \mathrm{C}$ using the same fixative solution. Brain tissues were transferred to $15 \%$ sucrose for $24 \mathrm{~h}$ before rinsing in 30\% sucrose for an additional $24 \mathrm{~h}$ at $4^{\circ} \mathrm{C}$. As shown in Figure 1, coronal sections $(20 \mu \mathrm{m})$ were prepared with a freezing microtome following the rat brain atlas of Paxinos and Watson (2004, 5th ed.) as follows: anterior cingulate cortex (bregma +2.16$)$, dorsomedial striatum (bregma +1.56$)$, NAc (bregma +1.56 ).

\section{Protein immunofluorescence}

For immuno-staining, tissue sections were first washed in $0.01 \mathrm{M}$ PBS $(3 \times 10 \mathrm{~min})$ and then incubated in 0.01 M PBS containing 10\% normal goat serum (NGS), $0.1 \%$ Triton X-100, and 3\% bovine serum albumin for $1 \mathrm{~h}$ to decrease non-specific staining. The sections were then incubated for $24 \mathrm{~h}$ at $4^{\circ} \mathrm{C}$ in $0.01 \mathrm{M}$ PBS containing anti$\triangle$ FosB (SC-48; 1:400; Santa Cruz) or anti-pCREB rabbit polyclonal antibody (06-519; 1:400; Millipore). Unbound primary antibodies were washed in $0.01 \mathrm{M}$ PBS $(3 \times$ $10 \mathrm{~min}$ ) prior to $24 \mathrm{~h}$ incubation at $4^{\circ} \mathrm{C}$ with FITC- 
conjugated goat anti-rabbit secondary antibody (1:400; Sigma-Aldrich) followed rinse in PBS for $3 \times 10 \mathrm{~min}$. Finally, 4', 6'-diamidino-2-phenylindole (DAPI) was added to label nuclei, and the sections were mounted with mounting medium for fluorescence observation.

\section{Image analysis}

Quantification of $\triangle$ FosB and PCREB immuno-reactivity was conducted using a Leica TCS-SP2 (Leica Instruments, Germany) laser confocal microscope set at 40x magnification and counted by an observer blind to treatment conditions with the Image-Pro Plus software. For all regions, a size of $0.125 \mathrm{~mm}^{2}$ area was counted for each section in each hemisphere. Thus there were a total of six sample areas which were counted for each animal (i.e., 1 sample area/2 hemispheres/3 sections). The counts from all six sample areas from a particular region were averaged to obtain a mean number of immunoreactive cells $/ 0.125 \mathrm{~mm}^{2}$.

\section{Statistical analysis}

Data were expressed as mean \pm SEM and were analyzed by Graph Pad Prism (Version 5.0) software. The results from the acquisition and expression of the CPP test were analyzed using one-way ANOVA followed by the Bonferroni's multiple comparison tests. The data from immunofluorescence experiments were analyzed with two-way ANOVA followed by Bonferroni post-tests. Repeated measurement of twoway ANOVA was conducted followed by Bonferroni posttest to assess the differences of CPP scores in extinction of CPP. Values of $\mathrm{p}<0.05$ were considered statistically significant.

\section{Abbreviations \\ ACC: Anterior cingulate cortex; CAMP: Cyclic adenosine monophosphate; CPP: Conditioned place preference; CREB: CAMP response element binding protein; D1 receptor: Dopamine type 1 receptor; D2 receptor: Dopamine type 2 receptor; DMS: Dorsomedial striatum; GABA: Gamma aminobutyric acid; MSNs: Medium spiny neurons; NAc: Nucleus accumbens; PDE: Phosphodiesterase; SNc: Substantia nigra pars compacta; VTA: Ventral tegmental area.}

\section{Competing interests}

The authors declare that they have no competing interests.

\section{Authors' contributions}

GW, EF, and XZ were responsible for the study concept and design. YM, ZR, $\mathrm{J}$, and BG contributed to the animal experiments. YM, ZR, and LZ contributed to the immunofluorescence experiments. BG drawn the figures. $Y M, Z R$, and $X Z$ were responsible for data analysis and interpretation of findings. Ying Mu drafted the manuscript and $X Z$ revised it. All authors critically reviewed content and approved final version for publication.

\section{Acknowledgement}

This work was financially supported by grants from the National Science Foundation of China (81130023, 81373382), National Basic Research Plan (973) of the Ministry of Science and Technology of China (2009CB522000, 2011CB5C4403). Supports from Priority Academic Program Development of Jiangsu Higher Education Institutes (PAPD) and Grant from Jiangsu Science and Technology commission (BM2013003) are also appreciated.

\section{Author details}

${ }^{1}$ Jiangsu Key laboratory for Translational Research and Therapy for Neuropsycho-disoders \& Department of Pharmacology, College of Pharmaceutical Sciences, Soochow University, 199 Ren'ai Road, Suzhou 215123, Jiangsu Province, China. ${ }^{2}$ Department of Physiology, Pharmacology \& Neuroscience, CUNY Medical School, New York, NY, USA.

\section{Received: 16 December 2013 Accepted: 12 September 2014}

\section{7.}

\section{References}

1. Shoblock JR, Wichmann J, Maidment NT: The effect of a systemically active ORL-1 agonist, Ro 64-6198, on the acquisition, expression, extinction, and reinstatement of morphine conditioned place preference. Neuropharmacology 2005, 49:439-446.

2. Aguilar MA, Rodríguez-Arias M, Miñarro J: Neurobiological mechanisms of the reinstatement of drug-conditioned place preference. Brain Res Rev 2009, 59:253-277.

3. Tzschentke TM: Measuring reward with the conditioned place preference (CPP) paradigm: update of the last decade. Addict Biol 2007, 12:227-462.

4. Mueller D, Perdikaris D, Stewart J: Persistence and drug-induced reinstatement of a morphine-induced conditioned place preference. Behav Brain Res 2002, 136:389-397.

5. Ribeiro Do Couto B, Aguilar MA, Manzanedo C, Rodriguez-Arias M, Minarro J: NMDA glutamate but not dopamine antagonists blocks drug-induced reinstatement of morphine place preference. Brain Res Bull 2005, 64:493-503.

6. Wei $X L$, Su RB, Lu XQ, Liu Y, Yu SZ, Yuan BL, Li J: Inhibition by agmatine on morphine-induced conditioned place preference in rats. Eur J Pharmacol 2005, 515:99-106.

7. Xie Z, Adamowicz WO, Eldred WD, Jakowski AB, Kleiman RJ, Morton DG, Stephenson DT, Strick CA, Williams RD, Menniti FS: Cellular and subcellular localization of PDE10A, a striatum-enriched phosphodiesterase. Neuroscience 2006, 139:597-607.

8. Seeger TF, Bartlett B, Coskran TM, Culp JS, James LC, Krull DL, Lanfear J, Ryan AM, Schmidt CJ, Strick CA, Varghese AH, Williams RD, Wylie PG, Menniti FS: Immunohistochemical localization of PDE10A in the rat brain. Brain Res 2003, 985:113-126.

9. Humphries MD, Prescott TJ: The ventral basal ganglia, a selection mechanism at the crossroads of space, strategy, and reward. Prog Neurobiol 2010, 90:385-417.

10. Hebb AL, Robertson HA, Denovan-Wright EM: Phosphodiesterase 10A inhibition is associated with locomotor and cognitive deficits and increased anxiety in mice. Eur Neuropsychopharmacol 2008, 18:339-363.

11. Schmidt CJ, Chapin DS, Cianfrogna J, Corman ML, Hajos M, Harms JF, Hoffman WE, Lebel LA, McCarthy SA, Nelson FR, Proulx-LaFrance C, Majchrzak MJ, Ramirez AD, Schmidt K, Seymour PA, Siuciak JA, Tingley FD 3rd, Williams RD, Verhoest PR, Menniti FS: Preclinical characterization of selective phosphodiesterase 10A inhibitors: a new therapeutic approach to the treatment of schizophrenia. J Pharmacol Exp Ther 2008, 325:681-690

12. Cador M, Bjijou Y, Cailhol S, Stinus L: D-amphetamine-induced behavioral sensitization: implication of a glutamatergic medial prefrontal cortex-ventral tegmental area innervation. Neuroscience 1999, 94:705-721.

13. Robison AJ, Nestler EJ: Transcriptional and epigenetic mechanisms of addiction. Nat Rev Neurosci 2011, 12:623-637.

14. Ma YY, Meng L, Guo CY, Han JS, Lee DY, Cui CL: Dose- and time-dependent, context-induced elevation of dopamine and its metabolites in the nucleus accumbens of morphine-induced CPP rats. Behav Brain Res 2009, 204:192-199.

15. Zhang D, Zhang $H$, Jin GZ, Zhang $K$, Zhen $X$ : Single dose of morphine produced a prolonged effect on dopamine neuron activities. Mol Pain 2008, 4:57

16. Nakagawa T, Suzuki Y, Nagayasu K, Kitaichi M, Shirakawa H, Kaneko S: Repeated exposure to methamphetamine, cocaine or morphine induces augmentation of dopamine release in rat mesocorticolimbic slice co-cultures. PLoS One 2011, 6:e24865.

17. Sanchez CJ, Bailie TM, Wu WR, Li N, Sorg BA: Manipulation of dopamine d1-like receptor activation in the rat medial prefrontal cortex alters stress- and cocaine-induced reinstatement of conditioned place preference behavior. Neuroscience 2003, 119:497-505.

18. Thompson BE, Sachs BD, Kantak KM, Cherry JA: The Type IV phosphodiesterase inhibitor rolipram interferes with drug-induced conditioned place preference 
but not immediate early gene induction in mice. Eur J Neurosci 2004, 19:2561-2568

19. Kam AY, Liao D, Loh HH, Law PY: Morphine induces AMPA receptor internalization in primary hippocampal neurons via calcineurin-dependent dephosphorylation of GluR1 subunits. J Neurosci 2010, 30:15304-15316.

20. Briand LA, Blendy JA: Molecular and genetic substrates linking stress and addiction. Brain Res 2010, 1314:219-234.

21. Carlezon WA Jr, Duman RS, Nestler EJ: The many faces of CREB. Trends Neurosci 2005, 28:436-445

22. Moron JA, Gullapalli S, Taylor C, Gupta A, Gomes I, Devi LA: Modulation of opiate-related signaling molecules in morphine-dependent conditioned behavior: conditioned place preference to morphine induces CREB phosphorylation. Neuropsychopharmacology 2010, 35:955-966.

23. Nestler EJ, Barrot M, Self DW: DeltaFosB: a sustained molecular switch for addiction. Proc Natl Acad Sci U S A 2001, 98:11042-11046.

24. Sim-Selley LJ, Cassidy MP, Sparta A, Zachariou V, Nestler EJ, Selley DE: Effect of DeltaFosB overexpression on opioid and cannabinoid receptor-mediated signaling in the nucleus accumbens. Neuropharmacology 2011, 61:1470-1476.

25. Nestler EJ: Molecular mechanisms of drug addiction. Neuropharmacology 2004, 47(Suppl 1):24-32.

26. MCDaid J, Dallimore JE, Mackie AR, Napier TC: Changes in accumbal and pallidal pCREB and deltaFosB in morphine-sensitized rats: correlations with receptor-evoked electrophysiological measures in the ventral pallidum. Neuropsychopharmacology 2006, 6:1212-1226.

27. Grauer SM, Pulito VL, Navarra RL, Kelly MP, Kelley C, Graf R, Langen B, Logue S, Brennan J, Jiang L, Charych E, Egerland U, Liu F, Marquis KL, Malamas M, Hage T, Comery TA, Brandon NJ: Phosphodiesterase 10A inhibitor activity in preclinical models of the positive, cognitive, and negative symptoms of schizophrenias. J Pharmacol Exp Ther 2009, 331:574-590.

28. McClung CA, Ulery PG, Perrotti LI, Zachariou V, Berton O, Nestler EJ: DeltaFosB: a molecular switch for long-term adaptation in the brain. Brain Res Mol Brain Res 2004, 132:146-154.

29. Barrot M, Olivier JD, Perrotti LI, DiLeone RJ, Berton O, Eisch AJ, Impey S, Storm DR, Neve RL, Yin JC, Zachariou V, Nestler EJ: CREB activity in the nucleus accumbens shell controls gating of behavioral responses to emotional stimuli. Proc Natl Acad Sci U S A 2002, 99:11435-11440.

30. Harlan RE, Kailas SR, Tagoe CE, Garcia MM: Morphine actions in the rat forebrain: role of protein kinase C. Brain Res Bull 2004, 62:285-295.

31. Manzanedo C, Aguilar MA, Rodriguez-Arias M, Minarro J: Effects of dopamine antagonists with different receptor blockade profiles on morphine-induced place preference in male mice. Behav Brain Res 2001 , 121:189-197.

32. Nunez C, Gonzalez-Cuello A, Sanchez L, Vargas ML, Milanes MV, Laorden ML: Effects of rolipram and diazepam on the adaptive changes induced by morphine withdrawal in the hypothalamic paraventricular nucleus. Eur J Pharmacol 2009, 620:1-8.

33. Liddie $\mathrm{S}$, Anderson $\mathrm{KL}$, Paz A, Itzhak $Y$ : The effect of phosphodiesterase inhibitors on the extinction of cocaine-induced conditioned place preference in mice. J Psychopharmacol 2012, 26:1375-1382.

34. Crawford CA, Villafranca SW, Cyr MC, Farley CM, Reichel CM, Gheorghe SL, Krall CM, McDougall SA: Effects of early methylphenidate exposure on morphine- and sucrose-reinforced behaviors in adult rats: relationship to dopamine D2 receptors. Brain Res 2007, 1139:245-253.

35. Taracha E, Chrapusta SJ, Lehner M, Skorzewska A, Maciejak P, Szyndler J, Plaznik A: Morphine and methadone pre-exposures differently modify brain regional Fos protein expression and locomotor activity responses to morphine challenge in the rat. Drug Alcohol Depend 2008, 97:21-32.

36. Philibin SD, Hernandez A, Self DW, Bibb JA: Striatal signal transduction and drug addiction. Front Neuroanat 2011, 5:60.

37. Sotty F, Montezinho LP, Steiniger-Brach B, Nielsen J: Phosphodiesterase $10 \mathrm{~A}$ inhibition modulates the sensitivity of the mesolimbic dopaminergic system to D-amphetamine: involvement of the D1-regulated feedback control of midbrain dopamine neurons. J Neurochem 2009, 109:766-775.

38. Brunzell DH, Mineur YS, Neve RL, Picciotto MR: Nucleus accumbens CREB activity is necessary for nicotine conditioned place preference. Neuropsychopharmacology 2009, 34:1993-2001.
39. Chauvet $C$, Lardeux $V$, Jaber $M$, Solinas $M$ : Brain regions associated with the reversal of cocaine conditioned place preference by environmental enrichment. Neuroscience 2011, 184:88-96.

40. Chartoff EH, Barhight MF, Mague SD, Sawyer AM, Carlezon WA Jr: Anatomically dissociable effects of dopamine D1 receptor agonists on reward and relief of withdrawal in morphine-dependent rats. Psychopharmacology (Berl) 2009, 204:227-239.

doi:10.1186/s13041-014-0070-1

Cite this article as: Mu et al:: Inhibition of phosphodiesterase10A attenuates morphine-induced conditioned place preference. Molecular Brain 2014 7:70.

\section{Submit your next manuscript to BioMed Central and take full advantage of:}

- Convenient online submission

- Thorough peer review

- No space constraints or color figure charges

- Immediate publication on acceptance

- Inclusion in PubMed, CAS, Scopus and Google Scholar

- Research which is freely available for redistribution

Submit your manuscript at www.biomedcentral.com/submit
C) BioMed Central 